\title{
Telehealth in rheumatology: the 2021 Arab League of Rheumatology Best Practice Guidelines
}

\author{
Nelly Ziade ${ }^{1,2}$ - Ihsane Hmamouchi ${ }^{3,4} \cdot$ Lina el Kibbi $^{5} \cdot$ Melissa Daou $^{6} \cdot$ Nizar Abdulateef $^{7} \cdot$ Fatemah Abutiban $^{8}$. \\ Bassel Elzorkany ${ }^{9}$. Chafia Dahou-Makhloufi ${ }^{10}$. Wafa Hamdi ${ }^{11}$. Samar Al Emadi ${ }^{12}$. Hussein Halabi ${ }^{13}$. \\ Khalid A. Alnaqbi ${ }^{14,15}$. Sima Abu Al Saoud ${ }^{16}$. Soad Hashad ${ }^{17,18}$. Radouane Niamane ${ }^{19} \cdot$ Manal El Rakawi $^{20}$. \\ Layla Kazkaz ${ }^{21}$. Sahar Saad ${ }^{22,23} \cdot$ Mervat Eissa $^{9} \cdot$ Ilanca Fraser ${ }^{24} \cdot$ Basel Masri $^{25}$
}

Received: 30 October 2021 / Accepted: 23 December 2021 / Published online: 6 January 2022

(c) The Author(s), under exclusive licence to Springer-Verlag GmbH Germany, part of Springer Nature 2022

\begin{abstract}
To develop Best Practice Guidelines (BPG) for the use of Telehealth in Rheumatology in the Arab region, to identify the main barriers and facilitators of telehealth, and to provide rheumatologists with a practical toolkit for the implementation of telehealth. Guidelines were drafted by a core steering committee from the Arab League of Associations for Rheumatology (ArLAR) after performing a literature search. A multidisciplinary task force (TF), including 18 rheumatologists, 2 patients, and 2 regulators from 15 Arab countries, assessed the BPG using 3 rounds of anonymous online voting by modified Delphi process. The statements were included in the final BPG without further voting if $\geq 80 \%$ of TF members indicated high agreement. The voting on barriers and facilitators was performed through one voting round. The toolkit was developed based on available literature and discussions during the Delphi rounds. Four General Principles and twelve Statements were formulated. A teleconsultation was specifically defined for the purpose of these guidelines. The concept of choice in telehealth was highlighted, emphasizing patient confidentiality, medical information security, rheumatologist's clinical judgment, and local jurisdictional regulations. The top barrier for telehealth was the concern about the quality of care. The toolkit emphasized technical aspects of teleconsultation and proposed a triage system. The ArLAR BPG provide rheumatologists with a series of strategies about the most reliable, productive, and rational approaches to apply telehealth.
\end{abstract}

Keywords Rheumatology $\cdot$ Best practice $\cdot$ Guidelines $\cdot$ Telehealth $\cdot$ Telemedicine

This project was not intended as a medical research project, or to assist with the preparation of any representative statistics to be published. Consequently, no regulatory approvals have been obtained in connection with this project and the survey. Task Force members did not receive any fees for their participation in the project.

Previous Publication: The manuscript was published by the same authors as a pre-print on the medRxiv website on August 24th, 2021 (https://doi.org/10.1101/2021.08.18.21262218).

Nelly Ziade

nellziade@yahoo.fr; nelly.zoghbi@usj.edu.lb;

drnellyziade@gmail.com

Extended author information available on the last page of the article

\section{Introduction}

Telehealth services were projected to light with the emergence of the Coronavirus Disease 19 (COVID-19) pandemic in 2020, as the demand for telehealth largely exceeded the supply [1-3]. Even though this high demand may decline once the pandemic has ended, the need for telehealth services will most likely persist in the future.

The clinical applications of telehealth are diverse. It is currently available in various settings, including emergency departments, inpatient hospital wards, intensive care units, and pharmacies [4]. In addition, significant advancements in technology have established telehealth as a feasible option for managing patients with rheumatic diseases. Studies indicate how the use of telerheumatology in certain settings has successfully increased patient access to specialty care, with good patient and provider satisfaction $[5,6]$. 
Surveys were conducted by the Arab League of Associations for Rheumatology (ArLAR) to study the impact of the COVID-19 pandemic on patients with chronic rheumatic diseases and on rheumatologists in 16 Arab countries. These surveys identified telehealth as a significant unmet need in patient management $[3,7]$. The successful implementation of telehealth can assist rheumatologists in providing continuity of care for patients who face obstacles that restrict their access to in-person treatment. However, the lack of a structural framework for telerheumatology has been identified as a barrier to the effective implementation of telehealth in the rheumatology clinic [8]. Best Practice Guidelines (BPG) for telerheumatology can provide the necessary framework to facilitate teleconsultation as they add credibility, standardize approaches, decrease liability and facilitate reimbursement of this novel health service [9]. Nevertheless, BPG for performing telehealth services in rheumatology (and practical advice for their implementation) are lacking.

The primary objective of this study was to develop BPG for the use of Telehealth In RheumatOLogy (TIROL study) in the Arab region. The secondary objectives were to identify the main barriers to telehealth and the key facilitators of telehealth in the ArLAR countries, and to provide rheumatologists with a practical toolkit for the implementation of telehealth services in the rheumatology clinic.

\section{Methods}

The BPG were developed under the umbrella of the ArLAR, in line with the Appraisal of Guidelines for REsearch \& Evaluation (AGREE II) instrument [10]. A core steering committee (SC), comprising of seven authors, performed a computerized literature search of four sources that were available in the central study site (PubMED, American College of Rheumatology (ACR), American Telemedicine Association, and World Health Organization websites) to identify available guidelines and studies using keywords "telerheumatology", "telemedicine" and "guidelines". The literature search was conducted in November 2020, covered articles published in the English language, between 2001 and 2020, and identified 1494 potentially eligible studies (Fig. 1). Of these, 50 relevant articles were included. Information from these articles provided guidance in formulating the guideline statements. Based on the available published rheumatology guidelines (as well as those in other specialties), general principles (GP) and best practice statements (BPS) were drafted by two authors (NZ and MD).

Four GPs and 12 BPS were formulated; levels of evidence were indicated according to the Oxford Centre for EvidenceBased Medicine [11]. The draft was validated by the core $\mathrm{SC}$ and reviewed and edited by the ArLAR scientific committee, a law firm advisor, and an ACR telemedicine expert. Thereafter, a multidisciplinary task force (TF) (representing 16 Arab countries) comprising of 18 rheumatologists (16 from the Arab Adult Arthritis Awareness (AAAA) group, a special interest group from ArLAR and two ArLAR advisors), two patients with rheumatic diseases), two regulators/ payers (one from the public sector and the other from the private sector) convened online to assess the BPG using three rounds of voting by a modified Delphi process (www.calib rum.com) (Fig. 1).

The levels of evidence and the decision rules were explained to the TF during a briefing meeting 2 weeks prior to the first round of voting. Taskforce members reported their level of agreement during each round of voting using a numerical rating scale:one (complete disagreement) to nine (complete agreement). Participants were able to give

Fig. 1 Study flowchart

Literature Review
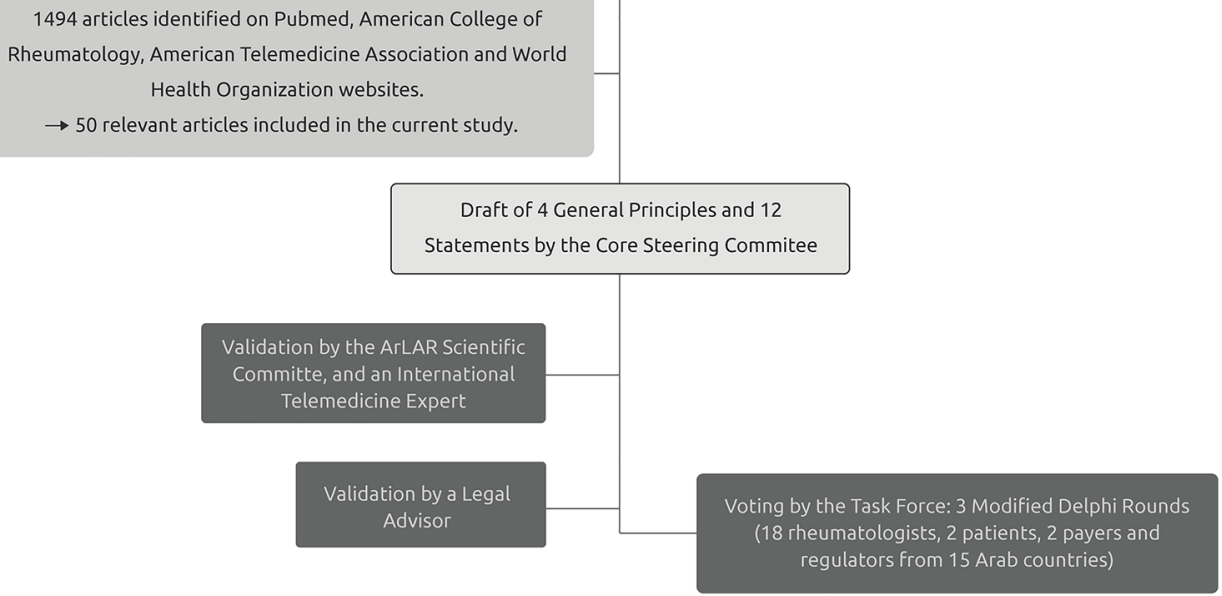
qualitative comments. Revisions to the GP and BPS were made by the SC through an iterative process until consensus was reached. The criteria for moving from one Delphi round to another, and for selecting the final statement, were guided by the OMERACT recommendations [12]. GP and BPS were included in the final BPG without further voting if $\geq 80 \%$ of TF members indicated high agreement (7-9). All GP and BPS that scored $\geq 50 \%$ high agreement (7-9) and $\leq 15 \%$ low agreement (1-3) and all items that required rephrasing were included in the next round of voting. The criteria to select a GP and BPS in the final round were $\geq 70 \%$ high agreement (7-9) and $\leq 15 \%$ low agreement (1-3). All of the $22 \mathrm{TF}$ members participated in each of the 3 rounds of voting. All votes were anonymous and weighted equally.

Information from the literature review supported the SC in identifying the main physician and patient-related barriers to telehealth and the key facilitators. These items were adapted to the Arab region and formulated into short statements. Before evaluating the BPG, TF members were asked to rank the barriers and facilitators of telerheumatology in the Arab region from one (most important barrier or facilitator) to five (least important barrier or facilitator). One round of anonymous voting on barriers and facilitators was conducted through the Surveylet platform.

Based on the literature review and discussions with the TF during the voting rounds, the SC proposed a practical toolkit for the possible implementation of telehealth services in the rheumatology clinic.

\section{Results}

The final BPG are presented in Table 1, with the accompanying level of evidence (LoE), consensus, and agreement (LoA) for each round of voting. All GP and BPS reached $\geq 80 \%$ consensus by the end of the third round (Supplementary Table 1).

\section{General principles}

\section{General principle A: definition of a teleconsultation (LoE 5; LoA 8.14; Consensus 100\%)}

Adapted from the American Telemedicine Association's definition of "telemedicine" $[4,12,13]$ the definition of a teleconsultation was established specifically for these guidelines as: "A rheumatology teleconsultation is a synchronous exchange of medical information between a patient and a rheumatologist via audio or audiovisual electronic communication, to improve the patient's health status", where "medical information" includes medical history, physical exam, review of test results and the final prescription and "synchronous" refers to a real-time exchange between the patient and the physician via video, audio or text [14].

The TF is aware that the definition of teleconsultation may vary in each country. Notably, teleconsultation is differentiated from e-consultation, which is an exchange of medical information between two healthcare providers via electronic audiovisual communication to improve a patient's health status. Therefore, e-consultations are not within the scope of the current BPG.

\section{General principle B: access and continuity of care (LoE 3; LoA 8.41; Consensus $100 \%$ )}

Telehealth may improve the access and continuity of care for patients with rheumatic diseases who are home-bound, live in remote areas or under-served communities, or who need to adhere to social distancing restrictions This principle is supported by the ACR Position statement on telemedicine [15] and is especially true in the era of COVID-19. Studies have shown that measures related to the containment of the COVID-19 pandemic, like national lockdowns and social distancing restrictions, led to a perceived delay between symptom onset and a first rheumatological visit [2]. Several international surveys also found that, during the COVID-19 pandemic, $10 \%$ to $25 \%$ of patients with rheumatic diseases stopped their chronic medication, thus compromising the treat-to-target strategies. This emphasizes the need for an alternative to in-clinic visits $[1-3,16]$.

This principle is also supported by the results from a survey conducted with 75 rheumatologists in the Netherlands during the COVID-19 pandemic, which found that continuity of care was guaranteed through telephone and video consultations by $99 \%$ and $9 \%$ of the respondents, respectively [17]. Another survey conducted with 426 established patients and 74 physicians found that virtual video visits (VVVs) were vastly preferred to office visits by patients for convenience and travel time, while the majority (52.5\%) of clinicians reported higher efficiency of a VVV appointment [18].

\section{General principle C: Improving disease outcomes (LoE 2; LoA 7.86; Consensus $86.36 \%$ )}

Telehealth can help some patients adhere to the management plan, and this is likely to improve disease outcomes in some selected disease states Using a proper triage system for telehealth in rheumatology, early detection and early referral may improve disease outcomes, especially in diseases like rheumatoid arthritis (RA) where there is a limited window of opportunity for early management. By facilitating the application of the treat-to-target strategy in RA and other chronic diseases (e.g., gout), telehealth is likely to support adherence to therapy and maintaining treatment tar- 
Table 1 General principles and best practice guidelines statements for telehealth in rheumatology

\begin{tabular}{|c|c|c|c|c|}
\hline & & LoE* & $\begin{array}{l}\text { Consensus** } \\
(\%)\end{array}$ & $\begin{array}{l}\text { LoA*** } \\
\text { Mean }(\mathrm{SD})\end{array}$ \\
\hline \multicolumn{5}{|l|}{ General principles } \\
\hline A Definition of a teleconsultation & $\begin{array}{l}\text { A rheumatology teleconsultation is a synchronous exchange of medical } \\
\text { information } ¥ \text { between a patient and a rheumatologist via audio or audio- } \\
\text { visual electronic communication, to improve the patient's health status }\end{array}$ & 5 & 100 & $8.14(0.77)$ \\
\hline B Access and Continuity of Care & $\begin{array}{l}\text { Telehealth may improve the access and continuity of care for patients } \\
\text { with rheumatic diseases who are home-bound, live in remote areas or } \\
\text { under-served communities, or who need to adhere to social distancing } \\
\text { restrictions }\end{array}$ & 3 & 100 & $8.41(0.80)$ \\
\hline $\mathrm{C}$ Improving disease outcomes & $\begin{array}{l}\text { Telehealth can help some patients adhere to the management plan, and this } \\
\text { is likely to improve disease outcomes in some selected disease states }\end{array}$ & 2 & 86.36 & $7.86(1.21)$ \\
\hline D Quality of medical care & $\begin{array}{l}\text { Rheumatologists need to use professional experience and judgment to } \\
\text { assess whether telehealth is suitable in each situation }\end{array}$ & 5 & 95.45 & $8.14(\mathrm{O} .89)$ \\
\hline \multicolumn{5}{|l|}{ Best Practice Statements } \\
\hline 1 Informed consent & $\begin{array}{l}\text { Before the teleconsultation visit, an informed consent should be obtained } \\
\text { from the patient, in writing or verbally; it should include an explanation, } \\
\text { in a simple language, of the benefits and risks of telehealth encounters, as } \\
\text { well as the conditions under which telehealth services may be terminated } \\
\text { and a referral made to in-person care }\end{array}$ & 5 & 90.91 & $7.86(1.28)$ \\
\hline 2 Confidentiality & $\begin{array}{l}\text { The use of telehealth services must ensure the patient's information security } \\
\text { and confidentiality }\end{array}$ & 5 & 100 & $8.82(0.50)$ \\
\hline 3 Documentation & $\begin{array}{l}\text { The provision of telehealth services should be well documented in the } \\
\text { patient's file, similarly to any in-person medical visit. The decision } \\
\text { to assess the patient remotely should be justified and recorded in the } \\
\text { patient's file }\end{array}$ & 5 & 100 & $8.77(0.43)$ \\
\hline 4 Shared decision and choice & $\begin{array}{l}\text { The choice of using telehealth services should be based on a shared deci- } \\
\text { sion between the patient and the physician. Patients should have a choice } \\
\text { of their provider of medical teleconsultation }\end{array}$ & 5 & 100 & $8.36(0.73)$ \\
\hline 5 Patient's physical examination & $\begin{array}{l}\text { Some parts of the physical exam might be performed remotely, e.g., } \\
\text { inspection and evaluation of the range of motion. The patient should } \\
\text { be instructed on how to be prepared for a remote physical exam, using } \\
\text { appropriate educational material }\end{array}$ & 2 & 90.91 & $7.77(1.02)$ \\
\hline 6 Patient-reported outcomes & $\begin{array}{l}\text { In some chronic rheumatic diseases, the use of patient-reported outcomes } \\
\text { by means of self-completed questionnaires adapted for telehealth can help } \\
\text { the physician make informed clinical decisions and improve the quality } \\
\text { of care }\end{array}$ & 3 & 100 & $7.73(0.77)$ \\
\hline 7 Safe Prescription & $\begin{array}{l}\text { The prescription should be transmitted in a safe and confidential manner to } \\
\text { the patient with a particular attention to avoiding abuse (of opioids and } \\
\text { narcotics' prescriptions in particular) }\end{array}$ & 5 & 95.45 & $8.05(0.90)$ \\
\hline 8 Fees and reimbursement & $\begin{array}{l}\text { The teleconsultation is subject to medical fees and reimbursement similar } \\
\text { to an in-person visit. Fees should be set before the teleconsultation }\end{array}$ & 5 & 100 & $8.45(0.60)$ \\
\hline 9 Ethical considerations & $\begin{array}{l}\text { Telehealth practice should conform to the same professional ethics that } \\
\text { govern in-person care and comply with local jurisdictional laws and } \\
\text { regulations of the physician's location }\end{array}$ & 5 & 100 & $8.59(0.60)$ \\
\hline 10 Rheumatologist training & $\begin{array}{l}\text { The rheumatologists are encouraged to receive proper training through } \\
\text { seminars, workshops, and conferences to familiarize with the advantages } \\
\text { and disadvantages of telehealth and to acquire strategies about the most } \\
\text { productive approach to remote medical care }\end{array}$ & 5 & 95.45 & $8.18(1.05)$ \\
\hline 11 Technical infrastructure and equity & $\begin{array}{l}\text { The technical infrastructure should be improved for patients and physicians, } \\
\text { to enable efficient and equitable access to telehealth services across the } \\
\text { countries and in vulnerable populations }\end{array}$ & 5 & 100 & $8.41(0.73)$ \\
\hline 12 Research & $\begin{array}{l}\text { Local and regional research projects to assess the implementation of tel- } \\
\text { ehealth and the resulting disease outcomes in the Arab region are strongly } \\
\text { encouraged }\end{array}$ & 5 & 95.45 & $8.32(1.04)$ \\
\hline
\end{tabular}

*LoE: Level of Evidence according to the Oxford Centre for Evidence-Based Medicine

${ }^{* *}$ Consensus: \% of votes with a score from 7 to 9

*** LoA: Level of agreement from 1 to 9 , with 9 being the highest agreement

${ }^{\ddagger}$ Exchange of medical information includes medical history, physical exam, review of test results and final prescription 
gets $[6,19]$. However, higher-quality randomized controlled trials are needed to demonstrate the effectiveness of different telerheumatology interventions in improving disease outcomes [20].

\section{General principle D: Quality of medical care (LoE 5; LoA 8.14; Consensus $95.45 \%$ )}

Rheumatologists need to use professional experience and judgement to assess whether telehealth is suitable in each situation Rheumatologists should use their judgement to decide whether a teleconsultation is appropriate in each case. They should ensure that the quality of care provided remotely via telehealth services is consistent with related in-person services while ensuring that the provided services are in alignment with the local laws and regulations where the rheumatologist is based. A guide for a triage system is proposed in the Toolkit section of this document (Fig. 2) [6, 19].

\section{Best practice statements}

\section{BPS 1: Informed consent (LoE 5; LoA 7.90; Consensus 90.91\%)}

Before the teleconsultation visit, an informed consent should be obtained from the patient, in writing or verbally; it should include an explanation, in a simple language, of the benefits and risks of telehealth encounters, as well as the conditions under which telehealth services may be terminated and a referral made to in-person care Some tel- ehealth providers may argue that when a patient electively chooses to visit a physician (whether it is a face-to-face visit or a teleconsultation) there is inherent informed consent and that official informed consent would only be required where the patient needs to undergo a procedure, or where patients are included in research trials. However, it should be emphasized that teleconsultation is a novel way of engaging with patients, and patients should be appropriately informed about the limitations and drawbacks of telehealth (e.g., misdiagnosis). The information provided to the patient should include the nature of the telehealth encounter, including any technical limitations or potential for disruption and contingency plans, the protection of patient identifiable information, and billing information(if appropriate). The patient should also be informed that there may be a possibility of the physician requesting the patient to attend an in-person visit where the physician considers such a visit to be more appropriate. The patient should be informed that they may withdraw consent from telehealth services at any point (before, during, or after the teleconsultation) [13, 21]. While the standards and requirements of informed patient consent may vary depending on the jurisdiction, it is recommended to keep electronic records of informed consent.

\section{BPS 2: Confidentiality (LoE 5; LoA 8.82; Consensus 100\%)}

The use of telehealth services must ensure the patient's information security and confidentiality This should include proper and mandatory measures to ensure online information security (e.g., anti-hacking measures, password-protected access) and visual and auditory privacy, in

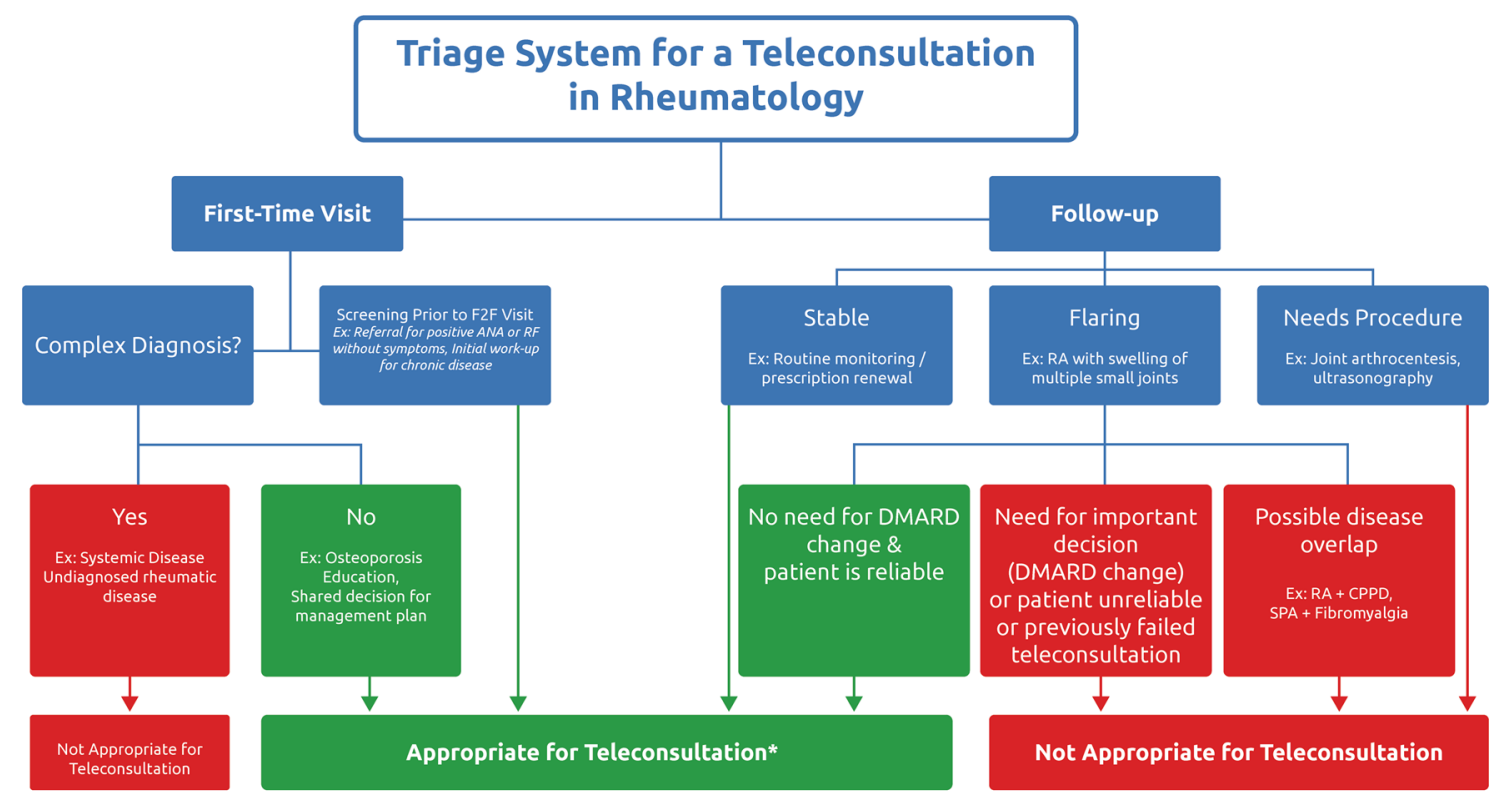

Fig. 2 Triage system for a teleconsultation in rheumatology. *Provided that the patient accepts teleconsultation 
both the patient's and the provider's environment. Unless both parties explicitly agree upon it, the teleconsultation should not be recorded, neither by the patient nor by the physician.

\section{BPS 3: Documentation (LoE 5; LoA 8.77; Consensus 100\%)}

The provision of telehealth services should be well documented in the patient's file, similarly to any in-person medical visit. The decision to assess the patient remotely should be justified and recorded in the patient's file It is recommended that providers of telehealth services have access to the patient's medical records, especially when the patient is unknown to them. Furthermore, the reasoning behind whether or not to assess the patient via teleconsultation should be clearly documented, and the patient's records should be updated accordingly [13, 22].

\section{BPS 4: Shared decision and choice (LoE 5; LoA 8.36; Consensus 100\%)}

The choice of using telehealth services should be based on a shared decision between the patient and the physician. Patients should have a choice of their provider of medical teleconsultation The patients should be allowed to choose whether or not they want to engage with their rheumatologist via teleconsultation, and to choose their telehealth provider without payers mandating the use of specified telehealth platforms or preferred providers with restrictive policies [13].

\section{BPS 5: Patient's physical examination (LoE 2; LoA 7.77; Consensus $90.91 \%$ )}

Some parts of the physical exam might be performed remotely, e.g., inspection and evaluation of the range of motion. The patient should be instructed on how to be prepared for a remote physical exam using appropriate educational material Physical examination is one of the pillars of medical reasoning in rheumatology; the inability to examine a patient might be viewed as a major obstacle. While physical attendance of the patient is preferable in some cases (e.g., a patient's first consultation where an accurate examination and diagnosis is essential) some parts of the physical exam might be performed via teleconsultation and can be facilitated by the appropriate instructions to the patient with regards to what clothing to wear, the position of the camera, and the proper use of furniture. In some instances, assistance from a proxy person (e.g., a family member) can be requested for the physical exam. Physicians can also send a brochure or video tutorial regarding the maneuvers that will be performed for the physical examination to the patient, before the teleconsultation [23-27]. It is recommended to translate and validate such tutorials in Arabic, with adaptation to local dialects where appropriate [23, 28].

BPS 6: Patient-reported outcomes (LoE 3; LoA 7.73; Consensus 100\%)

In some chronic rheumatic diseases, the use of patient-reported outcomes (PROs) by means of self-completed questionnaires adapted for telehealth can help the physician make informed clinical decisions and improve the quality of care In patients with an established disease, such as RA and spondyloarthritis, disease activity and functional status measures can be assessed before the teleconsultation using self-completed questionnaires of PROs [29, 30]. Studies have shown that among RA patients with low disease activity (LDA) or remission, a PROs-based telehealth follow-up for tight control of disease activity in RA can achieve similar disease control as a conventional outpatient follow-up [31]. RA Impact of Disease (RAID) score, in particular, has been shown to function well as a $\mathrm{PRO}$ in routine care, where patients with RAID $<2$ have a high likelihood of being in remission/ LDA (as per the disease activity score) and, if pre-screened, could avoid a clinic visit [32]. However, the validity of PROs measures needs to be evaluated in dedicated studies. In addition, several PROs measures should be translated and validated in Arabic and adapted to the cultural level of the patient where possible.

\section{BPS 7: Safe Prescription (LoE 5; LoA 8.05; Consensus 95.45\%)}

The prescription should be transmitted in a safe and confidential manner to the patient with a particular attention to avoiding abuse (of opioids and narcotics prescriptions in particular) The risk of prescription abuse may be increased in a telehealth setting [33, 34]. Therefore, an efficient tracking system of prescriptions should be applied in an electronic health record system, in accordance with the legal framework of the country in which the rheumatologist is based. One such option is to have an electronic medical record allowing the physician to write the prescription electronically. However, some countries do not allow electronic signatures for prescriptions, especially for opioids and narcotics..

BPS 8: Fees and reimbursement (LoE 5; LoA 8.45; Consensus $100 \%)$

The teleconsultation is subject to medical fees and reimbursement similar to an in-person visit. Fees should be set before the teleconsultation The lack of a consensual reimbursement policy may be a significant deterrent to the adoption of telehealth. Therefore the physician and the legislator 
in the physician's country of practice should agree on a fair and transparent fee for a teleconsultation; these fees should be communicated to the patient before the visit [13].

Physicians should be aware of the fact that some patients might be unwilling to pay for an audio-only consultation, while some payers might be inclined to pay only a percentage of the conventional fee for teleconsultations that do not utilize video, e.g., $33 \%$ in UAE, $50 \%$ in Jordan, $80 \%$ in Bahrain (data were provided by the TF during the Delphi rounds and were limited to the country where it was available at the time of the study). Aside from the patient/payer perspective, some physicians might argue that teleconsultation can be more time-consuming than an in-person visit and that reimbursement should reflect the time spent with the patient. From an economic perspective, telehealth may decrease the indirect cost for the patient (e.g., saving on travel costs, time taken off from work) [19] and for the physician (by reducing the number of no-shows and appointment cancellations) $[35,36]$. By helping to maintain patients in remission or LDA through telemonitoring, the cost of managing chronic diseases would be substantially reduced [37].

\section{BPS 9: Ethical considerations (LoE 5; LoA 8.59; Consensus $100 \%)$}

Telehealth practice should conform to the same professional ethics that govern in-person care and comply with local jurisdictional laws and regulations of the physician's location Advancements in technology have facilitated the use of telehealth and Information Technology in the treatment or rehabilitation of diseases. However, increased use of technology is accompanied by threats to patients' personal information. Therefore, special consideration to the ethical issues involved in telehealth practice, including confidentiality and security, doctor-patient relationship, and informed consent, are crucial to guarantee safe use while maintaining the quality of healthcare services [38].

\section{BPS 10: Training of rheumatologists (LoE 5; LoA 8.18; Consensus 95.45\%)}

The rheumatologists are encouraged to receive proper training through seminars, workshops, and conferences to familiarize with the advantages and disadvantages of telehealth and to acquire strategies about the most productive approach to remote medical care A lack of adequate training and familiarity with telehealth can be a barrier to the successful adoption thereof [39]. Therefore, it is recommended that rheumatologists and their staff educate themselves on all aspects of telehealth through continued professional development [39]. Although professional development and training can be of value to the physician, its effectiveness on the outcomes of teleconsultations needs to be further evaluated.

BPS 11: Improve infrastructure and promote equity (LoE 5; LoA 8.41; Consensus 100\%)

The technical infrastructure should be improved for patients and physicians, to enable efficient and equitable access to telehealth services across the countries and in vulnerable populations. Studies in the Middle East have shown that poor infrastructure was associated with low adoption of telehealth in the region [40]. This is especially true for patients living below the poverty line, as research indicates that access to telehealth is challenging for these vulnerable populations [1]. On the other hand, telehealth can decrease inequities by offering easier access to care for patients living in rural or remote areas, and supporting continuity of care. Rheumatologists should therefore identify limitations of the technical infrastructure in their region and take appropriate steps to attempt to overcome such limitations, where feasible.

Consideration should be given to implementing a secure platform that would allow the patient to make an appointment with their physician of choice, engage in teleconsultation, obtain the required prescription and diagnostic tests and pay the fees to the physician.

\section{BPS 12: Support research projects in telehealth in the Arab Region (LoE 5; LoA 8.32; Consensus 95.45\%)}

Local and regional research projects to assess the implementation of telehealth and the resulting disease outcomes in the Arab region are strongly encouraged Recommendations from the Middle East also highlight the need for health initiatives to focus on health education and promotion, to raise awareness of the benefits of telehealth services in the region [39].

\section{Top barriers and facilitators to telehealth}

Voting on the top physician and patient-related barriers and facilitators to Telehealth in Rheumatology in the Arab region [1, 5, 18, 19, 23, 31, 35, 39-46] revealed that concern about the quality of care and proper communication, and internal and external technical difficulties, were regarded as the top patient and physician-related barriers. Lack of alternatives when social distancing is required, and increased access to care, were voted as the top physician and patient-related facilitators to telehealth, respectively (Table 2). 
Table 2 Top Physician- and Patient-related Barriers- and Facilitators to Telehealth in Rheumatology in the Arab region

\begin{tabular}{|c|c|}
\hline Choice Rank & Top Physician-related Barriers to Telehealth in Rheumatology in the Arab region \\
\hline 1 & $\begin{array}{l}\text { Concern about the quality of care (impossible to do a complete clinical exam, lack of non-verbal communication, } \\
\text { patient distraction during the visit) }\end{array}$ \\
\hline 2 & External technical difficulties such as poor internet connection or suitable equipment \\
\hline 3 & Internal technical difficulties such as lack of familiarity with e-Health, and lack of trained staff \\
\hline 4 & Lack of motivation (lack of reimbursement) \\
\hline 5 & Absence of legal framework: inter-country licensure laws, need for credentialing at multiple sites, and liability concerns \\
\hline Choice rank & Top physician-related facilitators to telehealth in rheumatology in the Arab region \\
\hline 1 & Lack of alternatives when social distancing measures are needed \\
\hline 2 & Better time management, reducing crowded waiting rooms and waiting lists \\
\hline 3 & Less appointment cancellation and no-shows \\
\hline 4 & Better quality of care for close monitoring of chronic diseases \\
\hline 5 & Efficient triage of patients \\
\hline Choice rank & Top patient-related barriers to telehealth in rheumatology in the Arab region \\
\hline 1 & Concern about the quality of care or proper communication \\
\hline 2 & Internal technical difficulties such as lack of familiarity with technology \\
\hline 3 & External technical difficulties such as poor internet connection or unsuitable equipment \\
\hline 4 & Resistance to change \\
\hline 5 & Lack of motivation or unclear benefit (patient lives near the healthcare facility, elderly patient with more spare time) \\
\hline Choice rank & Top patient-related facilitators to telehealth in rheumatology in the Arab region \\
\hline 1 & Increased access to care and/or possibility to obtain specialist medical opinion from remotely based expert physicians \\
\hline 2 & Lack of alternatives when social distancing measures are needed \\
\hline 3 & Less travel costs \\
\hline 4 & Quick communication and reassurance from the physician \\
\hline 5 & Better time management \\
\hline
\end{tabular}

\section{Practical toolkit for the implementation of telehealth}

A Triage System for a Teleconsultation in Rheumatology (Fig. 2) was developed to assist rheumatologists in assessing whether telehealth is suitable in each situation, based on the complexity of the diagnosis, the patient's clinical status, and disease prognosis. Rheumatologists need to use their professional experience and judgement to assess whether telehealth is suitable in each situation while ensuring that the services provided comply with the laws and regulations of their respective countries. In addition, a practical toolkit for the possible implementation of teleconsultation in rheumatology was developed to provide guidance on how to translate theory into practice, highlighting the activities to perform before, during, and after the teleconsultation (Fig. 3).

\section{Discussion}

The ArLAR BPG for telehealth were developed to inform rheumatologists about the advantages and limitations of telehealth and to provide them with a series of strategies to practice telehealth in the rheumatology clinic.

The need for practical ways to provide remote health care has been highlighted during the COVID-19 pandemic, where social distancing and potential risks to patient safety have prohibited regular in-person consultations. In that setting, telehealth can be a valuable tool for managing patients with rheumatic disease, especially more vulnerable patients with co-morbidities and other risk factors [47]. In addition, recent studies suggest that telehealth services could positively impact on disease activity, medication adherence, physical activity, and self-efficacy levels in patients with RA, 


\section{Toolkit for implementation of telehealth in the rheumatology clinic}

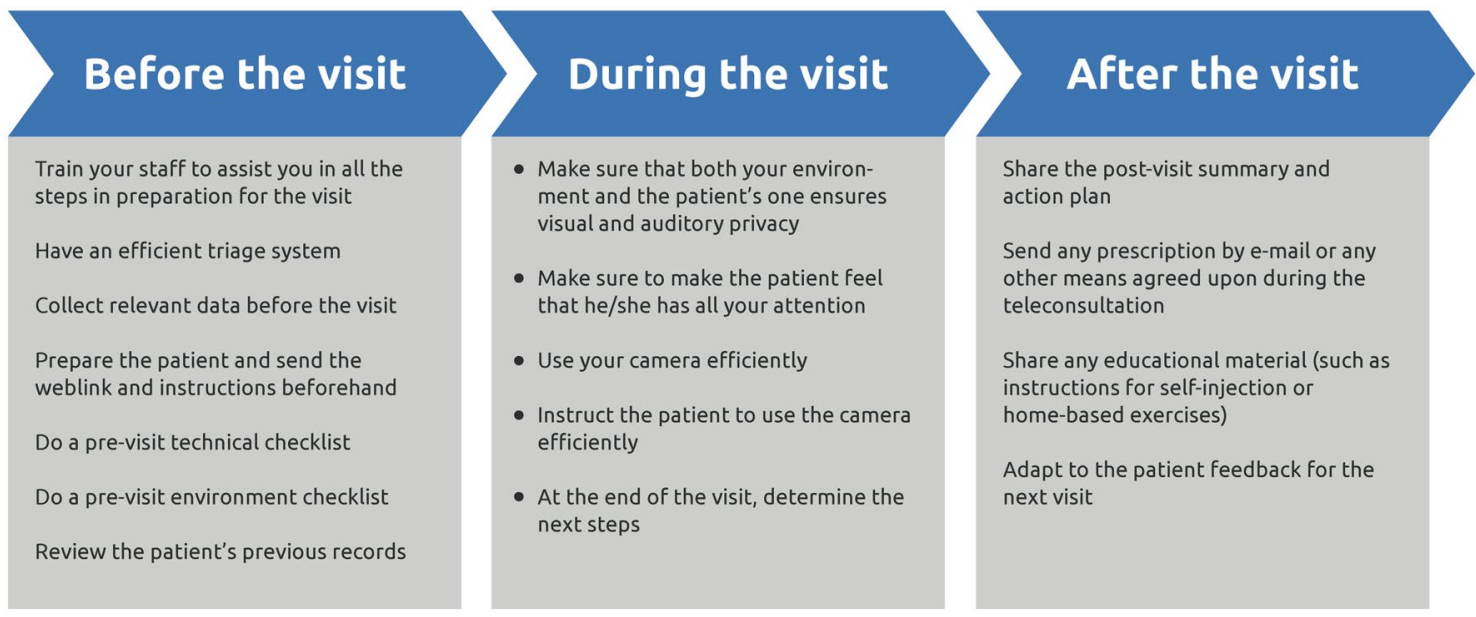

Fig. 3 Toolkit for the implementation of telehealth in the rheumatology clinic. *Technical checklist: Check if your device and browser support the telehealth platform. Check if your internet is stable. Check sound and webcam on your device. Have a backup plan if the connection fails. Take time to familiarize yourself with the telehealth platform and its functions. Ensure all your devices are charged and have the chargers handy in case your battery drain; Close other apps/

provided these interventions are well-designed, versatile, and adaptive [48].

While some studies have found telehealth to be generally effective for the diagnosis and self-management of rheumatic disease (with mostly positive patient and provider satisfaction) $[14,48]$, others have found that it was associated with diagnostic delay, reduced likelihood of changing existing immunosuppressive therapy, earlier requirement for review and a lower likelihood of discharge, even though it led to improved appointment attendance [49].

This highlights the notion that the appropriateness of telerheumatology in patients' care may vary widely, differing by age, phase of illness, severity of symptoms, and rheumatic disease type. Furthermore, the effects of telerheumatology on patient access and the outcome of rheumatic disease across race, ethnicity, or socioeconomic status have not been explicitly studied in literature and may be difficult to predict [50]. In a study evaluating the patient's feelings about changing from a face-to-face consultation to a virtual one, only $76 \%$ of patients had the means to access a teleconsultation. The proportion of internet access and the agreement for a teleconsultation decreased in patients over 70 years old. The factors associated with an acceptance for teleconsultation were the significant distance from the consultation site and a higher level of education.

The TIROL Steering Committee acknowledges the significant disparity between countries in terms of available laws and legislation that manage telehealth and that any programs before the visit to improve speed/connectivity. **Environment checklist: Set up your workspace so that you are front-lit, the camera view covers approximately your head and shoulders, and the camera is at eye height. Make sure the background is not distracting. You might consider using a virtual background with your hospital logo or design. Dress professionally

guidelines will always be subject to compliance with the applicable laws and regulations of each ArLAR country. Rheumatologists are encouraged to actively participate in the effort to sensitize legislators to the interest and benefit of telerheumatology. Focusing on the patient- and physicianrelated barriers in the Arab region can assist authorities in establishing appropriate strategies for promoting telehealth. Moreover, the committee acknowledges the disparity in internet accessibility, electricity stability, and technology skills across the Arab countries, which are critical to consider when deciding whether telehealth is an appropriate method of providing health care. In the absence of clear evidence, rheumatologists should use their professional experience and judgment to assess whether telehealth is suitable in each situation while always prioritizing security and confidentiality considerations.

In summary, the ArLAR BPG provide a conceptual framework for the application of telehealth in rheumatology practice. Most of the statements were based on a low level of evidence and expert opinion, highlighting the need for further dedicated research to recognize the advantages and limitations of telehealth in rheumatology and for a subsequent update of these BPG in the future. The ArLAR BPG for telehealth are not intended to compel the use of telehealth in the same manner for every patient in every case; but are rather designed to provide the rheumatologists with a series of strategies about the most reliable, productive, and rational approaches to apply telehealth in the rheumatology 
setting, and principally in the context of pressing pandemic restrictions.

Supplementary Information The online version contains supplementary material available at https://doi.org/10.1007/s00296-021-05078-w.

Acknowledgements The authors would like to acknowledge the following people for their contribution to this study: Dr. Christine Peoples, the patients, regulators, payers and rheumatologists who participated in the Delphi survey, including Dr. Nazih El Kouartey and Dr. Lara Haddadin. We also thank Pfizer Gulf FZ LLC for providing an unrestricted educational grant to fund the medical writing and Delphi platform for this project and Taylor Wessing $\odot$ for providing legal advice.

Funding The study was funded by an unrestricted research grant from Pfizer Gulf FZ LLC, covering the fees of medical writing and Delphi panel platform.

\section{Declarations}

Conflict of interest One of the co-authors is a medical writer from the company Value in Research, which received funding from Pfizer to organize the Delphi process and medical writing. All the other authors didn't receive any financial support for this study.

Ethical approval Not required.

\section{References}

1. Mehta B, Jannat-Khah D, Fontana MA et al (2020) Impact of COVID-19 on vulnerable patients with rheumatic disease: results of a worldwide survey. RMD Open 6:1-6. https://doi.org/10.1136/ rmdopen-2020-001378

2. Dejaco C, Alunno A, WjBijlsma J et al (2021) Influence of COVID-19 pandemic on decisions for the management of people with inflammatory rheumatic and musculoskeletal diseases: a survey among EULAR countries. Ann Rheum Dis 80:518-526. https://doi.org/10.1136/annrheumdis-2020-218697

3. Ziadé N, el Kibbi L, Hmamouchi I et al (2020) Impact of the COVID-19 pandemic on patients with chronic rheumatic diseases: a study in 15 Arab countries. Int J Rheum Dis 23:1550-1557. https://doi.org/10.1111/1756-185X.13960

4. Schreiweis B, Pobiruchin M, Strotbaum V et al (2019) Barriers and facilitators to the implementation of eHealth services: systematic literature analysis. J Med Internet Res 21:1-12. https:// doi.org/10.2196/14197

5. Shenoi S, Hayward K, Curran ML et al (2020) Telemedicine in pediatric rheumatology: this is the time for the community to embrace a new way of clinical practice. Pediatr Rheumatol 18:1-4. https://doi.org/10.1186/s12969-020-00476-Z

6. Kulcsar Z, Albert D, Ercolano E, Mecchella JN (2016) Telerheumatology: a technology appropriate for virtually all. Semin Arthritis Rheum 46:380-385. https://doi.org/10.1016/j.semarthrit.2016. 05.013

7. Ziadé N, Hmamouchi I, el Kibbi L et al (2020) The impact of COVID-19 pandemic on rheumatology practice: a cross-sectional multinational study. Clin Rheumatol 39:3205-3213. https://doi. org/10.1007/s10067-020-05428-2

8. Muehlensiepen F, Knitza J, Marquardt W et al (2021) Acceptance of telerheumatology by rheumatologists and general practitioners in Germany: Nationwide cross-sectional survey study. J Med Internet Res. https://doi.org/10.2196/23742

9. Krupinski E, Bernard J (2014) Standards and guidelines in telemedicine and telehealth. Healthcare 2:74-93. https://doi.org/10. 3390/healthcare2010074

10. Brouwers MC, Kho ME, Browman GP et al (2010) AGREE II: Advancing guideline development, reporting and evaluation in health care. CMAJ 182:839-842. https://doi.org/10.1503/cmaj. 090449

11. Oxford Centre for Evidence-Based Medicine (2011) OCEBM Levels of Evidence Working Group. The Oxford Levels of Evidence 2. https://www.cebm.ox.ac.uk/resources/levels-of-evidence/ ocebm-levels-of-evidence. Accessed 16 Aug 2021

12. Boers M, Kirwan J, Tugwell P, Beaton D, Bingham CO III, Conaghan PG et al. (2015) The OMERACT Handbook. https://omera cthandbook.org/handbook. Accessed 16 Aug 2021

13. American Telemedicine Association (2020) Telemedicine defined. https://www.americantelemed.org/ata-news/what-is-telemedicineexactly/\#.VquyglLMbbo. Accessed 16 Aug 2021

14. McDougall JA, Ferucci ED, Glover J, Fraenkel L (2017) Telerheumatology: a systematic review. Arthritis Care Res (Hoboken) 69:1546-1557. https://doi.org/10.1002/acr.23153

15. American College of Rheumatology (2020) Telemedicine position statement. https://www.rheumatology.org/Portals/0/Files/Telem edicine-Position-Statement.pdf. Accessed 16 Aug 2021

16. Rosenbaum JT, Hamilton HCD et al (2020) Biologics, spondylitis and COVID-19. Ann Rheum Dis 79:1663-1665

17. Bos WH, Van Tubergen A, Vonkeman HE (2021) Telemedicine for patients with rheumatic and musculoskeletal diseases during the COVID-19 pandemic; a positive experience in the Netherlands. Rheumatol Int 41:565-573. https://doi.org/10.1007/ s00296-020-04771-6

18. Donelan K, Barreto EA, Sossong S et al (2019) Patient and clinician experiences with telehealth for patient follow-up care. Am J Manag Care 25:40-44

19. Roberts LJ, Lamont EG, Lim I et al (2012) Telerheumatology: an idea whose time has come. Intern Med J 42:1072-1078. https:// doi.org/10.1111/j.1445-5994.2012.02931.x

20. Piga M, Cangemi I, Mathieu A, Cauli A (2017) Telemedicine for patients with rheumatic diseases: systematic review and proposal for research agenda. Semin Arthritis Rheum 47:121-128. https:// doi.org/10.1016/j.semarthrit.2017.03.014

21. Mckoy K, Antoniotti NM, Armstrong A et al (2016) Practice Guidelines for Teledermatology. Telemed e-Health 22:981-990. https://doi.org/10.1089/tmj.2016.0137

22. Howgego G, Sharma I, Kalu P (2020) The rules for online clinical engagement in the COVID era. J Plast Reconstr Aesthetic Surg 73:2127-2135. https://doi.org/10.1016/j.bjps.2020.08.045

23. Ziade N, Arayssi T, Elzorkany B et al (2021) Development of an educational video for self-assessment of patients with RA: steps, challenges, and responses. Mediterr J Rheumatol 32:66-73. https://doi.org/10.31138/mjr.32.1.66

24. Laskowski E, Johnson S, Shelerud R et al (2020) The telemedicine musculoskeletal examination. Mayo Clin Proc 95:1715-1731

25. Gossec L, Fayet F, Soubrier M et al (2019) Is self-assessment by patients of disease activity acceptable over the long term in rheumatoid arthritis? A 3-year follow-up of 771 patients. Rheumatol (UK) 58:1498-1499. https://doi.org/10.1093/rheumatology/ kez094

26. Shaffu S, Edwards J, Neame R, Hassan W (2013) Self-assessment of 28-joint disease activity scores by patients with rheumatoid arthritis on anti-TNF therapy. Rheumatol (UK) 52:576-578. https://doi.org/10.1093/rheumatology/kes383

27. Wahezi S, Duarte RA, Yerra S et al (2020) Telemedicine during COVID-19 and beyond: a practical guide and best practices multidisciplinary approach for the orthopedic and neurologic pain 
physical examination. Pain Physician 23:S205-S237. https://doi. org/10.36076/PPJ.2020/23/S205

28. Ziadé N, Saad S, Al Mashaleh M et al (2021) Perceptions of patients with rheumatoid arthritis about self-assessment of disease activity after watching an educational video: a qualitative pilot study from the AUTO-DAS in Middle Eastern Arab countries project. Rheumatol Int 41:733-740. https://doi.org/10.1007/ s00296-021-04799-2

29. England BR, Barber CEH, Bergman M et al (2020) Brief report: adaptation of american college of rheumatology rheumatoid arthritis disease activity and functional status measures for telehealth visits. Arthritis Care Res (Hoboken) 73:1909-1814. https:// doi.org/10.1002/acr.24429

30. Taylor PC (2020) Adopting PROs in virtual and outpatient management of RA. Nat Rev Rheumatol 16:477-478. https://doi.org/ 10.1038/s41584-020-0449-6

31. de Thurah A, Stengaard-Pedersen K, Axelsen M, Fredberg U, Schougaard LMV, Hjollund NHI, Pfeiffer-Jensen M, Laurberg TB, Tarp U, Kirsten Lomborg TM (2017) A tele-health follow-up strategy for tight control of disease activity in rheumatoid arthritis: results of the non-inferiority randomised controlled trail (the TeRA study). Arthritis Care Res (Hoboken) 70:2-28. https://doi. org/10.1002/acr

32. Mistry J, Sharif M, Prideaux A et al (2020) Use of rheumatoid arthritis impact of disease (RAID) in routine care; identification of DAS28 remission and unmet patient-reported outcomes. Rheumatol Adv Pract 4:1-6. https://doi.org/10.1093/rap/rkaa013

33. Lin LA, Fortney JC, Bohnert ASB et al (2021) Comparing telemedicine to in-person buprenorphine treatment in US veterans with opioid use disorder. J Subst Abuse Treat. https://doi.org/10. 1016/j.jsat.2021.108492

34. Wang L, Weiss J, Ryan EB et al (2021) Telemedicine increases access to buprenorphine initiation during the COVID-19 pandemic. J Subst Abuse Treat 124:337-339. https://doi.org/10. 1016/j.jsat.2020.108272

35. Freed J, Binks R, Kolsi J (2018) Telemedicine: is it really worth it? A perspective from evidence and experience. J Innov Heal Inf 25:14-18

36. Kessler EA, Sherman AK, Becker ML (2016) Decreasing patient cost and travel time through pediatric rheumatology telemedicine visits. Pediatr Rheumatol 14:1-6. https://doi.org/10.1186/ s12969-016-0116-2

37. Beresniak A, Gossec L, Goupille P et al (2011) Direct cost-modeling of rheumatoid arthritis according to disease activity categories in France. J Rheumatol 38:439-445. https://doi.org/10.3899/ jrheum.100589

38. Langarizadeh M, Moghbeli F, Aliabadi A (2017) Application of ethics for providing telemedicine services and information technology. Med Arch (Sarajevo, Bosnia Herzegovina) 71:351-355. https://doi.org/10.5455/medarh.2017.71.351-355
39. Al-Samarraie H, Ghazal S, Alzahrani AI, Moody L (2020) Telemedicine in Middle Eastern countries: progress, barriers, and policy recommendations. Int J Med Inform 141:104232. https:// doi.org/10.1016/j.ijmedinf.2020.104232

40. Matsumoto RA, England BR, Mastarone G et al (2020) Rheumatology clinicians' perceptions of telerheumatology within the veterans health administration: a national survey study. Mil Med 185:E2082-E2087. https://doi.org/10.1093/milmed/usaa203

41. Cavagna L, Zanframundo G, Codullo V et al (2021) Telemedicine in rheumatology: a reliable approach beyond the pandemic. Rheumatol (UK) 60:366-370. https://doi.org/10.1093/rheumatolo gy/keaa554

42. Smith WR, Atala AJ, Terlecki RP, Cam EK (2020) Implementation guide for rapid integration of an outpatient telemedicine program during the COVID-19 pandemic. J Am Coll Surg 231:216-222

43. Knitza J, Simon D, Lambrecht A et al (2020) Mobile health usage, preferences, barriers, and ehealth literacy in rheumatology: patient survey study. JMIR mHealth uHealth. https://doi.org/10.2196/ 19661

44. Teixeira V, Cordeiro I, Gonçalves MJ et al (2018) Telerheumatology - breaking barriers to access care in rheumatology. Acta Reumatol Port 2018:253-255

45. Dorsey ER, Topol EJ (2016) State of telehealth. N Engl J Med 375:154-161. https://doi.org/10.1056/nejmra1601705

46. Howren A, Aviña-Zubieta JA, Rebić N et al (2020) Virtual rheumatology appointments during the COVID-19 pandemic: an international survey of perspectives of patients with rheumatic diseases. Clin Rheumatol 39:3191-3193. https://doi.org/10.1007/ s10067-020-05338-3

47. Costa L, Tasso M, Scotti N et al (2021) Telerheumatology in COVID-19 era: a study from a psoriatic arthritis cohort. Ann Rheum Dis 80:2021. https://doi.org/10.1136/annrh eumdis-2020-217806

48. MacIver A, Hollinger H, Carolan C (2021) Tele-health interventions to support self-management in adults with rheumatoid arthritis: a systematic review. Rheumatol Int 41:1399-1418

49. Zhu W, De Silva T, Eades L et al (2021) The impact of telerheumatology and COVID-19 on outcomes in a tertiary rheumatology service: a retrospective audit. Rheumatol (UK) 60:3478-3480

50. McDougall J (2021) Leveraging telemedicine as an approach to address rheumatic disease health disparities. Rheum Dis Clin N Am 47:97-107

Publisher's Note Springer Nature remains neutral with regard to jurisdictional claims in published maps and institutional affiliations.

\title{
Authors and Affiliations
}

\author{
Nelly Ziade ${ }^{1,2}$ (1) Ihsane Hmamouchi ${ }^{3,4} \cdot$ Lina el Kibbi $^{5} \cdot$ Melissa Daou $^{6} \cdot$ Nizar Abdulateef $^{7} \cdot$ Fatemah Abutiban $^{8}$. \\ Bassel Elzorkany ${ }^{9}$. Chafia Dahou-Makhloufi ${ }^{10}$. Wafa Hamdi ${ }^{11}$. Samar Al Emadi ${ }^{12}$. Hussein Halabi ${ }^{13}$. \\ Khalid A. Alnaqbi ${ }^{14,15}$. Sima Abu Al Saoud ${ }^{16}$. Soad Hashad ${ }^{17,18} \cdot$ Radouane Niamane $^{19} \cdot$ Manal El Rakawi $^{20}$. \\ Layla Kazkaz $^{21} \cdot$ Sahar Saad $22,23 \cdot$ Mervat Eissa $^{9} \cdot$ Ilanca Fraser $^{24} \cdot$ Basel Masri $^{25}$
}

1 Rheumatology Department, Saint-Joseph Medical University, Beirut, Lebanon

2 Rheumatology Department, Hotel-Dieu de France Hospital, Alfred Naccache Blvd. Achrafieh, Beirut, Lebanon
3 Rheumatology Unit, Laboratory of Biostatistics, Clinical Research and Epidemiology (LBRCE), Temara Hospital, Rabat, Morocco 
4 Faculty of Medicine and Pharmacy, Mohammed V University, Rabat, Morocco

5 Rheumatology Division, Department of Internal Medicine, Specialized Medical Center, Riyadh, Saudi Arabia

6 Medicine Department, Faculty of Medicine, Saint-Joseph Medical University, Beirut, Lebanon

7 Rheumatology Unit, Department of Medicine, College of Medicine, University of Baghdad, Baghdad, Iraq

8 Rheumatology Unit, Department of Medicine, Jaber Alahmed Alsabah Hospital, Kuwait City, State of Kuwait

9 Rheumatology Department, Cairo University, Cairo, Egypt

10 Rheumatolology Department, Mohamed Lamine Debaghine University Hospital, Bab El Oued, Algiers, Algeria

11 Rheumatology Department, Kassab Institute of Orthopedics, UR17SP04, Faculty of Medicine of Tunis, Tunis El Manar University, Tunis, Tunisia

12 Rheumatology Department, Hamad Medical Corporation, Doha, Qatar

13 Rheumatology Department, King Faisal Specialist Hospital and Research Center, Jeddah, Saudi Arabia

14 Rheumatology Department, Tawam Hospital, Al Ain, UAE
15 Department of Internal Medicine, College of Medicine and Health Sciences, UAE University, Al Ain, UAE

16 Rheumatology Department, Makassed Hospital, East Jerusalem, Palestine

17 Rheumatology Department, Tripoli Children Hospital, Tripoli, Libya

18 Rheumatology Department, University of Tripoli, Tripoli, Libya

19 Rheumatology Department, Avicenne Military Hospital, Cadi Ayyd University, Marrakech, Morocco

20 Rheumatology Department, Faculty of Medicine, Douera Hospital, Saad Dahlab, Blida, Algeria

21 Rheumatology Department, Teshreen Hospital and Syrian Medical Association, Damascus, Syria

22 Rheumatology Department, Assiut University, Asyut, Egypt

23 Rheumatology Department, King Hamad University Hospital, Bahrain, Bahrain

24 Value in Research, Dubai, UAE

25 Rheumatology Division, Internal Medicine Department, Jordan Hospital, Amman, Jordan 